\title{
ZONAS CON POTENCIAL AGROTURÍSTICO EN LA REGIÓN CITRÍCOLA DE NUEVO LEÓN, MÉXICO: UN ANÁLISIS A PARTIR DEL ÁLGEBRA DE MAPAS ${ }^{1}$
}

\author{
Brenda Alcalá Escamilla \\ Álvaro López López \\ Instituto de Geografía. Universidad Nacional Autónoma de México
}

\section{RESUMEN}

La Región Citrícola de Nuevo León se caracteriza por una tradición agrícola de más de un siglo en el cultivo de naranjas, mandarinas y toronjas. No obstante, en los últimos años ha buscado diversificar y eslabonar la agricultura con el turismo. El objetivo del estudio fue identificar a través de un análisis de álgebra de mapas zonas con potencial agroturístico mediante la ubicación, coincidencia y concentración de la citricultura, la agroindustria, los recursos de interés turístico, la infraestructura básica, los servicios de vinculación turística y la accesibilidad.

Palabras clave: planeación, potencial turístico, álgebra de mapas, agroturismo.

\section{Areas with agritourism potential in the Citrus Region of Nuevo Leon, Mexico: A Map Algebra Analysis}

Recibido: 18 de junio de 2015

Devuelto para su revisión: 21 de diciembre de 2015

Aceptado: 5 de mayo de 2016

Departamento de Geografía Económica. Instituto de Geografía, UNAM. Circuito de Investigación Científica, Ciudad Universitaria, C.P. 04510, CIUDAD DE MÉXICO, D.F. E-mail: alcalaescamillabrenda@gmail.com, lopuslopez@igg.unam.mx

1 Este documento es resultado del proyecto IN306310, “Complejidad espacial de la región citrícola de Nuevo León en el entorno global”, financiado por el Programa de Apoyo a Proyectos de Investigación e Innovación Tecnológica (PAPIIT) DE LA Dirección General de Asuntos del Personal Académico (DGAPA) de la Universidad Nacional Autónoma de México (UNAM), coordinado por Álvaro López López.

2 Departamento de Geografía Económica. Instituto de Geografía, UNAM. Circuito de Investigación Científica, Ciudad Universitaria, C.P. 04510, Ciudad de México, D.F. E-mail: alcalaescamillabrenda@gmail.com, lopuslopez@igg.unam.mx 


\begin{abstract}
The citrus region of Nuevo Leon is characterized by an agricultural tradition of over a century in growing oranges, tangerines and grapefruits. However, in recent years it has sought to diversify its economy by hitching tourism to agriculture. The aim of the study was to identify, by means of a map algebra analysis, areas with potential for the development of agritourism. The location, coincidence and concentration of the citrus industry and of agribusiness were studied in relation to tourist places of interest, basic infrastructure, links to other industries and accessibility.
\end{abstract}

Keywords: Planning, tourism potential, map algebra, agritourism.

\title{
1. INTRODUCCIÓN
}

Desde la consolidación del turismo en los años setenta del siglo pasado, en México el turismo masivo de litoral ha sido el modelo dominante. Con inversiones del gobierno y de empresas extranjeras se crearon en zonas costeras los Centros Integralmente Planeados (CIP), grandes desarrollos turísticos que, como puede observarse en Cancún, Los Cabos, Loreto, Ixtapa y Huatulco, transformaron de manera considerable el paisaje natural y social de su entorno. Hoy día las políticas de desarrollo turístico continúan contemplando grandes proyectos, como la "Escalera Náutica del Mar de Cortés", la "Riviera Nayarit" o "Playa Espíritu" en Sinaloa (López; Cukier y Sánchez, 2006; Poder Ejecutivo Federal, 2007; Sectur, 2006 y 2007). No obstante, con el paso del tiempo se han hecho evidentes los impactos negativos del turismo masivo litoral en los órdenes ambiental, económico, social y cultural, lo cual ha llevado a replantear la dirección que debería seguir el turismo, a fin de disminuir sus efectos nocivos (Sectur, 2006).

La opción ha sido impulsar nuevos proyectos relacionados con el turismo alternativo, el cual se distingue por aprovechar los paisajes naturales, rurales y la diversidad biológica y cultural de los sitios. Tres tipos principales de turismo alternativo pueden identificarse: ecoturismo, turismo de aventura y turismo rural. En el caso de México, los dos primeros han logrado posicionarse poco a poco en el menú de la oferta turística nacional, sustentándose en la implementación de actividades recreativas en parques nacionales, reservas ecológicas, zonas montañosas, ríos, lagos y áreas costeras (Nieva, 2004; Ortiz, 2009, Sectur, op.cit. y 2007b). Por su parte, el turismo rural se encuentra en una posición más incipiente y se basa en el aprovechamiento de antiguas haciendas, áreas de cultivos y productos típicos mexicanos (tequila, mezcal, cacao y vainilla, entre otros), además de productos que aunque provenientes del exterior, han tenido arraigo en la cultura nacional, como la vid, el café y los quesos (Barrera, 2006; Ortiz, op.cit.). Aunque en términos macroeconómicos el turismo rural pareciera ser el menos rentable de los tres, representa una buena alternativa para mejorar el ingreso y propiciar la diversificación económica y el cuidado medioambiental.

Una de las modalidades de turismo rural en México son las rutas agroalimentarias vinculadas a un producto agropecuario o gastronómico regional característico con la intención 
de mostrar el proceso de producción a los visitantes y hacerlos participar en algunas tareas de la faena diaria, además de presentarles las artesanías y costumbres típicas del lugar. Una característica de este turismo es que incorpora varios sitios cercanos a la ruta, es decir, se relaciona con atractivos turísticos próximos, a partir de los cuales se conforman circuitos que benefician a una serie de localidades vecinas. A este tipo de actividades se le conoce como agroturismo (Bringas, 2010; Nieva, op. cit.).

Actualmente, el agroturismo ha alcanzado relevancia por su capacidad de revalorizar las zonas rurales y su cultura, lo cual ha conducido a múltiples estudios. Algunos ven al agroturismo como un complemento del desarrollo local que relaciona una actividad agropecuaria con el turismo para obtener beneficios económicos, sociales y mejoras en la infraestructura de las localidades receptoras (Constable y Oyarzun, 2007; Escudero, 2003; García, 2011; Hortelano, 2015; IICA, 2008; Meléndez, 2009; Ponce, 2009; Pulido y Cárdenas, 2011; Rivas, 2002; Vogel y Lombardo, 2004; WTO, 2004). Otros suelen tomar en cuenta las motivaciones existentes para diversificar las actividades primarias en las áreas seleccionadas y la manera de diseñar rutas con fines turísticos (Barrera, 2013; Blanco y Riveros, 2010; Lobo y Goldman, 1999; Paül y Araújo, 2012; Polovitz, 2001; Sánchez, Alcudia y Bejarano, 2005; Suchet, Jordan y Tuppen, 2011; Zamora y Grez, s.a.). Otros más tratan específicamente de las rutas agroalimentarias (Barrera, 2006, y 2013; Bringas, 2010; González, 2009 y 2011; Lopez y Tribak, 2013; Sosa y Salido, 2013), o buscan establecer las preferencias de las personas que visitan los sitios rurales (López y Barrena, 2013). Finalmente, están los estudios que buscan medir el cumplimiento de las expectativas al implementar una actividad vinculada al turismo rural (Sectur, 2007a; Solsona, 2014).

En México el turismo rural es incipiente. Entre los muchos espacios aprovechables para el agroturismo en el país se cuenta la Región Citrícola de Nuevo León. El cultivo de naranjas, mandarinas y toronjas que en el pasado ha impulsado diversas actividades industriales y comerciales, viene sufriendo a partir de los años ochenta del siglo pasado una desaceleración, lo que ha obligado a los gobiernos estatales y municipales a plantear nuevas estrategias para apoyar el crecimiento económico y el desarrollo regional. Una de estas estrategias es la implementación del agroturismo, modalidad del turismo alternativo que mediante la combinación de la agricultura tradicional con los recursos naturales y culturales (King, 2006 y 2009) permitiría rescatar la vocación citrícola de la región. Para que una actividad turística sea exitosa es menester elaborar modelos adecuados a las características físicas, ambientales, culturales y sociales del territorio, a fin de determinar si existe una vocación turística, qué tipo de turismo podría implementarse, y a qué mercado iría dirigido (Antón y González, 2005; Fernández, 2004).

El objetivo de esta investigación fue identificar en la Región Citrícola de Nuevo León las zonas con mayor potencial para el desarrollo de actividades agroturísticas. La evaluación se basó en la localización de los elementos que la posibilitan, por lo que fue necesario identificar: 1) las áreas de producción citrícola y agroindustrial, 2) los recursos turísticos existentes, 3) las localidades con infraestructura básica, 4) los servicios turísticos existentes, y 5) la accesibilidad de los sitios potenciales. Mediante un sistema de información geográfica, estos elementos se sometieron a un análisis de álgebra de mapas a fin 
de identificar áreas propicias al desarrollo de un producto turístico ${ }^{3}$ y otras en las que a corto y mediano plazo pudiera implementarse un agroturismo integrado y planeado que sirviera para impulsar el turismo en el resto de la región. El presente trabajo propone una metodología para determinar el potencial turístico mediante la localización e interrelación de los elementos indispensables para su promoción y consumo.

\section{MARCO TEÓRICO Y CONCEPTUAL}

\subsection{Multifuncionalidad de los espacios rurales}

En la década de los noventa del siglo pasado comenzó a replantearse el concepto productivista del campo como espacio dedicado principalmente a la producción agropecuaria destinada a abastecer a las ciudades de alimentos y materias primas. La nueva perspectiva planteó que en el campo hay cabida para otras actividades económicas, ecológicas y sociales, y ello condujo a revalorizar los espacios rurales y a someterlos al ordenamiento y la planificación territoriales a fin de aprovechar su potencial para nuevas actividades que beneficiaran a la población (Andrei y Darvasi, 2012; 2001; Webb, 2013).

El concepto de multifuncionalidad de los espacios rurales apareció por primera vez en la Conferencia de las Naciones Unidas sobre Medio Ambiente y Desarrollo, celebrada en Río de Janeiro en 1992 (Cumbre de Río) y se consolidó y difundió en la Unión Europea en la Declaración de Cork en 1996 (Andrei y Darvasi, op .cit.; Ledesma, 2014). La multifuncionalidad es la búsqueda de alternativas económicas complementarias a las actividades agrarias para producir nuevos bienes y servicios, con externalidades positivas y negativas. Desde este enfoque, el campo se víncula a tres funciones básicas: a) primaria o económica, relacionada con la producción de alimentos y materias primas; b) ambiental, relacionada con la conservación de los espacios naturales, la biodiversidad, la regeneración de los recursos naturales y la preservación de los paisajes rurales, soporte de las actividades recreativas; c) social y territorial, relacionada con la generación de empleos que evitan la emigración, protegen el patrimonio cultural y mejoran la calidad de vida (Andrei y Darvasi, op.cit.; Calatrava, 2009; Ledesma, op.cit.; Webb, op.cit.).

Estas funciones permitieron hablar de una nueva ruralidad con un modelo de agricultura integrado territorialmente a los recursos naturales y al reconocimiento de las demandas sociales. Su estrategia es la diversificación de las actividades productivas como alternativas para el desarrollo local mediante la generación de bienes privados (económicos) y públicos (sociales y ambientales). Actualmente, el turismo es visto como una opción complementaria a la agricultura y la ganadería, cuyos beneficios pueden ser: el aumento del ingreso familiar; la revalorización de los espacios rurales y naturales; la conservación y difusión de la cultura local, y la conservarción e impulso de las actividades primarias. Así, en distintas áreas rurales del mundo han comenzado a destinarse espacios al turismo rural (Andrei y Darvasi, op.cit; Horling y Marsden, op.cit; Ledesma, op.cit.).

3 Un producto turístico no se compone de un solo elemento, sino comprende un conjunto de bienes, servicios y entornos que los visitantes utilizan durante su viaje o estancia para satisfacer sus motivaciones de ocio y de vacaciones (Vera, López, et al., 2013). 


\subsection{Turismo rural y agroturismo}

El turismo rural es una modalidad del turismo alternativo que se caracteriza por llevarse a cabo en un ámbito campestre, lo cual da oportunidad a los visitantes de interactuar y conocer la forma de vida de las comunidades. La cultura rural se convierte así en el principal atractivo y se complementa con el medio natural que lo rodea. Las actividades recreativas son muy diversas y se caracterizan por ser participativas; es decir, el visitante toma parte en diferentes tareas de la vida cotidiana, trabaja en alguna de las faenas diarias del campo, participa en actividades culturales y religiosas o realiza actividades físicas. Una característica de este turismo es que a menudo se sobrepone con otros, por ejemplo, el ecoturismo, el turismo de aventura, el turismo cultural y el turismo urbano, entre otros (Sectur, 2007a; Vera, López, et al. 2013).

Aunque no existe consenso sobre el concepto de turismo rural, y los espacios varían de un país a otro, la Comisión Europea ha elaborado una serie de lineamientos que lo identifican como unas vacaciones en granjas y zonas rurales vinculadas a actividades turísticas endógenas ${ }^{4}$ relacionadas con el medio ambiente humano y natural (Vera, López, et al., op . cit.). En el caso de México, la Secretaría de Turismo (Sectur) lo ha definido como "los viajes que tienen como fin realizar actividades de convivencia e interacción con una comunidad rural en todas sus expresiones sociales, culturales y productivas cotidianas" (Nieva, 2004: 29). Tomando en cuenta las características de los espacios rurales en México se han reconocido las siguientes actividades: talleres artesanales, etnoturismo, ecoarqueología, vivencias místicas, aprendizaje de dialectos, fotografía rural, talleres gastronómicos, preparación y uso de medicina tradicional y agroturismo (Nieva, op. cit.; Sectur op. cit.).

El gobierno mexicano ve en el agroturismo una estrategia económica y social para apoyar el desarrollo de las comunidades rurales aprovechando las explotaciones agropecuarias. Este tipo de turismo busca el contacto personal con las actividades recreativas tradicionales con el objeto de que las personas conozcan y experimenten los procesos de producción, asimismo servicios de alojamiento, diversión, aprendizaje, gastronomía y comercialización de los productos tradicionales relacionados con la explotación agropecuaria (Boullon, 2008; Kasparek, 2009; Sectur; op. cit.; Sosa y Salido, 2013). Las rutas agroalimentarias se han desarrollado con gran éxito en países como Italia (viñedos y olivares); Francia (viñedos y hortalizas), Suiza (granjas, quesos) y España (quesos, jamones) (Bringas, 2010; González, 2011; Sosa y Salido, op. cit.). Mediante la combinación de actividades agropecuarias y agroindustriales con la gastronomía, los paisajes rurales, naturales, históricos y culturales, estas rutas resaltan la historia, la memoria y el origen de los cultivos o alimentos tradicionales de una región. En el caso de México se han establecido rutas vinculadas al cultivo del agave tequilero y mezcalero, del cacao y la vainilla, así como a viñedos y otras explotaciones agroindustriales. Algunos ejemplos son la Ruta del Vino y el Queso en Baja California y Querétaro, La Ruta del Chocolate en Tabasco, La Ruta del Tequila en Jalisco, y La Ruta de la Vainilla en Veracruz (Barrera, 2006; Barrera y Bringas, 2008; González, op. cit., Lizama, 2013).

4 Es decir, las tradiciones típicas de cada región. 


\section{MATERIALES Y MÉTODOS}

\subsection{Ubicación del área de estudio}

La Región Citrícola de Nuevo León se ubica en la zona centro sur del estado fronterizo del mismo nombre, en el noreste de México. Colinda con la Zona Metropolitana de Monterrey, la tercera ciudad más poblada de México y una de las urbes industriales más importantes de América Latina. Su territorio pertenece a dos provincias fisiográficas: 1) las llanuras costeras del Golfo Norte, caracterizadas por lomeríos suaves de extensión considerable y altitud promedio de 500 metros sobre el nivel del mar; y 2) la Sierra Madre Oriental, de plegamientos escarpados con altitudes máximas de tres mil metros sobre el nivel del mar (INEGI 2013).

La característica de la región es la actividad citrícola, que va desde el cultivo a la comercialización, pasando por el empaque y el procesamiento industrial. Los municipios que en este estudio se incluyeron como parte de la región son Allende, Montemorelos, Linares, Hualahuises y General Terán (Rocha-Peña, 2009; Sánchez, 1990; López et al., 2014).

\subsection{Elementos para la evaluación del potencial agroturístico}

La planeación de un sitio turístico se apoya en el ordenamiento territorial, que no sólo delimita áreas sino permite proponer acciones adecuadas para el aprovechamiento de un espacio específico con beneficios para la población (Antón et al., 2005; Fernández, 2004). El ordenamiento territorial permite corregir, disminuir o mitigar los impactos del turismo en los lugares en que se estableció sin planeación previa, o diseñar nuevos espacios. El primer paso es confirmar que el territorio posee los elementos básicos del sistema turístico, a saber: cercanía a un centro emisor de turistas; mecanismos públicos y privados que promocionen el producto; un sistema de transporte que proporcione conectividad y movilidad; un territorio que cuente con recursos turísticos; una sociedad que acepte la nueva actividad; la presencia de servicios turísticos (alojamiento, alimentación, transporte, comercio, etcétera), infraestructura y equipamiento básico. Es importante verificar la presencia de todos los elementos, ya que la ausencia de uno o más pueden dificultar el desarrollo de la actividad e impedir el éxito esperado (Alonso, 2002; Vera et al., 2013; Zárate y Rubio, 2005).

La evaluación del potencial turístico permite identificar los sitios más adecuados para una actividad económica concreta, especificando los requisitos, preferencias y variables deseadas (Antón y González; op . cit.; Fernández, op. cit.) y teniendo en cuenta las características del medio ambiente físico, los recursos sociales y los elementos superestructurales. Para la evaluación del potencial agroturístico de la Región Citrícola de Nuevo León se tomaron en cuenta los siguientes atributos:

a) Presencia del cultivo de cítricos.

b) Agroindustrialización de cítricos. 
c) Recursos naturales y humanos de interés turístico que complementen el atractivo de una ruta de este tipo (Kasparek, 2009; Sectur, s.a.-a; Sunyer et al., 2005; Vera et al., op. cit.).

d) Infraestructura básica (electricidad, agua potable, alcantarillado, saneamiento, comunicaciones y transporte). En el caso del agroturismo, es necesario adecuar las casas con todos estos elementos para alojar a los visitantes (Sectur, s.a.-b; Jafari, 2000).

e) Servicios turísticos existentes. La implementación de una actividad turística a corto plazo requiere de la presencia de una planta de servicios que permita atender las necesidades de hospedaje, alimentación y transportación de los visitantes (Kasparek, op. cit.).

f) Accesibilidad regional. Un aspecto esencial en la localización de las actividades turísticas es la existencia de una adecuada conexión entre los centros de mercado (procedencia de los turistas) y los espacios receptores de turistas (Ibídem).

\subsection{Metodología para la evaluación del potencial agroturístico}

La evaluación de potencial turístico comenzó con la localización de los elementos del sistema turístico en un área total de $64,084 \mathrm{~km}^{2}$. De gran importancia fue conocer la concentración o dispersión de los factores en el territorio que facilitan o dificultan la creación de productos turísticos. Se optó por la aplicación de una metodología basada en el análisis espacial que toma en cuenta los atributos del objeto de estudio. Los resultados obtenidos permiten describir, explicar y predecir (ESRI, 2006; Gómez y Barredo, 2006).

Se comenzó por colectar y ubicar la información de las variables seleccionadas (principalmente mediante recorridos de campo $)^{5}$ y se procedió a su captura en un programa de posicionamiento global (GPS) apoyado en procesos de digitalización y georreferenciación de datos por medio de un sistema de información geográfica (SIG). Posteriormente se elaboró la cartografía específica de cada variable a partir de las siguientes fuentes:

a) Las áreas citrícolas se obtuvieron de la información de superficie cosechada del Servicio de Información Agroalimentaria y Pesquera (SIAP) (Sagarpa, 2012), a partir de la cual se calculó la densidad de superficie cosechada de naranjas por municipio durante el año $2011^{6}$. La información de la agroindustria se adquirió mediante recorridos de superficie.

b) Los recursos de interés turístico se capturaron en un inventario que clasificó a los sitios en: a) lugares naturales de valor paisajístico, b) museos y manifestaciones culturales históricas, c) folklore (costumbres, leyendas, literatura, artesanías, gastronomía), d) realizaciones técnicas, científicas y artísticas contemporáneas, e) acontecimientos programados (Cárdenas, 2006; Minecitur, 2006; Valseca, 2009). Su identificación se realizó mediante trabajo de campo y revisión bibliográfica (Conarte Nuevo León, 2005 y 2006; Coronado y Quintanilla, 2008; Inafed, 2013;

5 El levantamiento de datos de campo se realizó del 26 de septiembre al 3 de octubre de 2010; del 26 de enero al 2 de febrero de 2011, y del 10 al 15 de noviembre de 2011.

6 La densidad se calculó a partir del número de hectáreas sembradas dividido entre la superficie total de cada uno de los municipios de estudio $\left(\mathrm{ha} / \mathrm{km}^{2}\right)$. 
Jiménez, 2010; King, 2006; Ordóñez, 2007). Para cada uno de los municipios se realizó una base de datos conformada por el nombre del recurso turístico, la categoría a la que pertenece, el tipo de actividades y su descripción.

c) Para la infraestructura de servicios básicos se seleccionaron las localidades que contaban con cobertura de energía eléctrica, agua, drenaje, Internet y teléfono. Los datos se obtuvieron de los Principales Resultados por Localidad ITER 2010 (INEGI, 2012a).

d) Los servicios turísticos se obtuvieron de la página web de la Secretaría de Turismo del Gobierno de Nuevo León, debido a que los establecimientos mencionados ahí son avalados por las autoridades estatales y operan bajo los estándares y requisitos necesarios para la atención de turistas (Gobierno del estado de Nuevo León, 2013). La infraestructura seleccionada incluyó hoteles, cabañas, restaurantes y centrales de autobuses.

e) La accesibilidad a la Región Citrícola se calculó mediante un análisis de isócronas ${ }^{7}$ realizado por medio de un SIG. Se tomaron en cuenta localidades mayores a 5 mil habitantes (INEGI, 2012a), la red carretera (federal, estatal y municipal) del Inventario Nacional de Infraestructura Terrestre (INIT) (SCT, 2012), y el modelo digital de elevación (INEGI, 2012b). A través de estas variables se calculó el tiempo aproximado de recorrido entre las localidades de la región y otras localidades cercanas, lo cual permitió determinar su proximidad relativa.

Una vez ubicados los elementos turísticos se procedió a establecer la concentración territorial de cada uno mediante un análisis de densidad de puntos $^{8}$ apoyado en un SIG. Las variables sometidas a este proceso fueron: a) presencia de la industria de cítricos, b) recursos de interés turístico, c) localidades con infraestructura de servicios básicos y d) establecimientos preestablecidos de apoyo turístico. En el caso de los cultivos de cítricos no fue necesario aplicar este análisis, ya que por sí mismo hace referencia a la densidad de los sembradíos. Por último, la accesibilidad no se realizó porque implica una medición de tiempo-distancia.

Finalmente, como el turismo se concibe como una actividad integrada y articulada (Barbini, 2003; Blanco, 2008), fue necesario emplear un análisis que mostrara las zonas que concentraban y relacionaban todos los factores, para así definir las áreas con mayor potencial agroturístico. El álgebra de mapas consiste en el proceso de datos geográficos a través de la integración de capas cartográficas para el diseño de esquemas de análisis de

7 Las isócronas son un indicador del tiempo de desplazamiento desde un punto determinado (por ejemplo, localidades, escuelas, hospitales) hacia el resto de la red. Se elaboran con base en los costos incurridos en el tiempo de desplazamiento, según las características de la infraestructura vial. El resultado son áreas con un mismo tiempo de recorrido (isócronas) que también pueden interpretarse como áreas de influencia de los nodos considerados. Dichas áreas indican que a mayor tiempo de desplazamiento, la accesibilidad será menor, y viceversa (ESRI, 2006).

8 En específico se aplicó un análisis de densidad de Kernel que permite calcular la densidad de las entidades de punto en la vecindad de cada celda ráster. Conceptualmente se ajusta a una superficie curva uniforme sobre cada punto. El valor de superficie es más alto en la ubicación del punto y disminuye a medida que aumenta la distancia respecto a éste, alcanzando un valor de cero en la distancia establecida de radio de búsqueda. Para calcular la densidad de cada celda ráster se agregan los valores de todas las superficies de Kernel que se superponen con el centro de cada celda (ESRI, 2006). 
datos espaciales a través de la aplicación de un conjunto de operadores que transforma una serie de entradas en una serie de salidas, dando como resultado la identificación de zonas poseedoras de ciertos rasgos de interés (ESRI, op. cit.; Moreno 2008).

Así pues, el análisis local consistió en generar una nueva capa a partir de otras mediante el método de superposición (ESRI, op. cit.; Moreno op. cit.), el cual permitió combinar la cartografía realizada para cada elemento a través de la sumatoria de todas las capas de densidad y la de accesibilidad. Se optó por sumar los mapas, ya que el objetivo era definir aquellas áreas que concentraran y relacionaran los atributos deseables en el mismo espacio. En el análisis de densidad los valores más altos indican concentración y los más bajos dispersión. Por su parte, el análisis de accesibilidad supuso la reclasificación de los valores obtenidos para dar un mayor peso a las distancias cortas de recorrido que a las largas; es decir, los valores esperados en cada una de las capas eran los más altos. Del resultado de la sumatoria se obtuvo una jerarquización de áreas de mayor a menor potencial agroturístico. Los valores altos representaron la concentración de todos los elementos (son las áreas con mayor potencial) y los valores intermedios la dispersión o la ausencia de alguno, por lo que se trata de espacios que necesitarán una mayor inversión para implementar una actividad turística. Finalmente, los valores bajos delimitan las áreas menos aptas por carecer de elementos que sustenten al agroturismo.

\section{RESULTADOS}

\subsection{Presencia del cultivo de cítricos}

La actividad citrícola de Nuevo León ha generado un paisaje de huertos frutales que ofrece una experiencia sensorial indispensable en el agroturismo. Aunado al aspecto contemplativo, el proceso productivo de cítricos es también un recurso de gran valor para el fomento del turismo. Algunas actividades de interés recreativo incluyen: conocer y observar el injerto de una especie de naranjo, el sistema de riego de las plantas, su desarrollo biológico, el surgimiento y degustación de los frutos, su cosecha o la participación en la pizca y caminatas entre los pasillos con los árboles colmados de flores o frutos. Por la cantidad de hectáreas sembradas de cítricos, los municipios en orden de importancia son: General Terán $(8,560.5$ ha), Linares $(4,500)$, Montemorelos $(3,560.4)$, Hualahuises (175) y Allende (70); mientras que por su densidad (hectáreas sembradas por kilómetro cuadrado), el orden sería: General Terán (3.48), Montemorelos (1.92), Linares (1.81), Hualahuises (1.38) y Allende (0.37) (Figura 1).

\subsection{Concentración de la agroindustria de cítricos}

La agroindustria es un complemento del agroturismo que puede aprovecharse a través de recorridos por las instalaciones de la fábrica en compañía de un guía que explique los procesos de transformación del cultivo y ofrezca la degustación del producto (Jafari, 2000; Lominé y Edmunds, 2007). En el caso de la Región Citrícola, la agroindustria se encuentra concentrada en tres áreas urbanas: Montemorelos, con cinco empacadoras, dos jugeras y una gajera; Linares, con una gajera y una empacadora, y Allende, con una jugera y una empacadora (Figura 1). 


\section{Figura 1 \\ DENSIDAD DE ÁREAS DEDICADAS A LA CITRICULTURA (2011) Y DENSIDAD DE INDUSTRIAS DE CÍTRICOS (2012)}

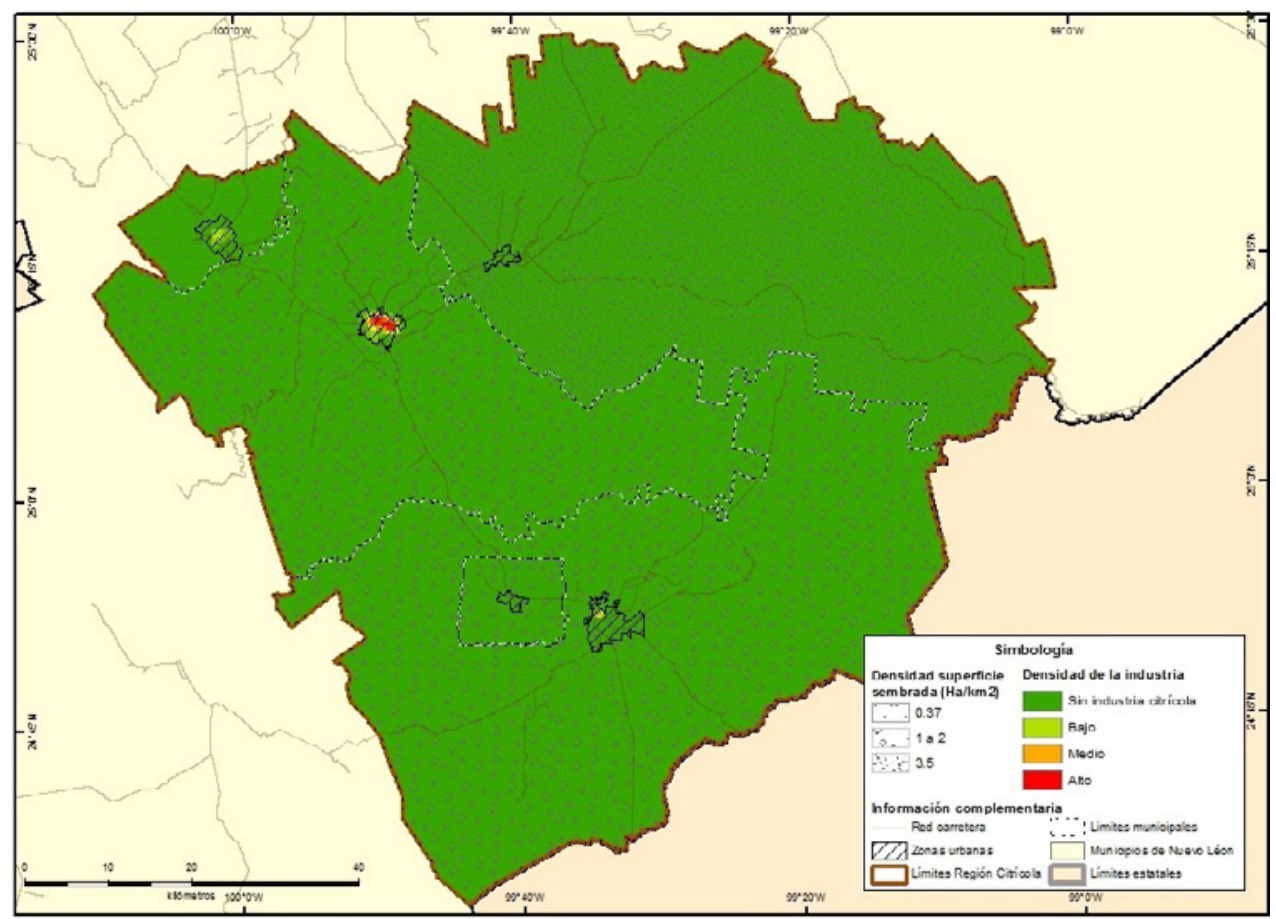

Fuente: elaboración propia.

\subsection{Recursos naturales y humanos de interés turístico}

En la Región Citrícola se identificaron 143 recursos de interés turístico, muchos de los cuales ya están constituidos como tales. La mitad de ellos son recursos naturales, y la otra mitad recursos humanos. Entre los primeros se cuentan la Sierra Madre Oriental, los ríos perennes y las extensas planicies, con una gran diversidad de paisajes e innumerables elementos de interés, como cañones, montañas, cuerpos de agua y vegetación, todos de gran demanda ecoturística y para el turismo de aventura. Entre los recursos humanos destacan los centros históricos de todas las cabeceras municipales, con edificios de la época colonial e independiente de México, algunos de los cuales están catalogados como monumento histórico por el Instituto Nacional de Antropología e Historia (INAH). Asimismo se encuentran los edificios religiosos y civiles de interés histórico en torno a las plazas centrales, puntos de máxima concentración de atractivos turísticos, debido en parte a que en muchos de ellos se han instalado museos regionales. Finalmente, en todas las cabeceras municipales se realizan múltiples celebraciones y ferias a lo largo del año, incluidas las fiestas patronales. El folklore se expresa en artesanías de madera y piel, así 
como en una gastronomía ligada a la producción agropecuaria regional. Entre los atractivos contemporáneos identificados están el parque Estrella, el autódromo de Montemorelos y un lugar donde se practica el juego conocido como "gotcha".

A nivel municipal Montemorelos concentra 35 por ciento de los recursos de interés turístico de la región, además de contar con la mayor diversidad de recursos naturales y humanos. Linares cuenta con 24 por ciento, General Terán con 17 por ciento, Allende con 16 por ciento y Hualahuises únicamente con ocho por ciento del total de los recursos. Además de la distribución, se identificó la concentración y dispersión de los recursos, los cuales se aglomeran sobre todo en las zonas urbanas municipales y se diseminan por la Sierra Madre Oriental y hacia el poniente de la Región Citrícola. La mayor parte de los elementos turísticos (48 por ciento) se agrupa en las áreas de baja concentración de recursos, 32 por ciento en las áreas de densidad muy alta, 10 por ciento en las áreas de densidad media, nueve por ciento en las de densidad alta, y uno por ciento en las de muy baja densidad. (Figura 2).

\section{Figura 2}

\section{CONCENTRACIÓN DE RECURSOS DE INTERÉS TURÍSTICO (2012)}

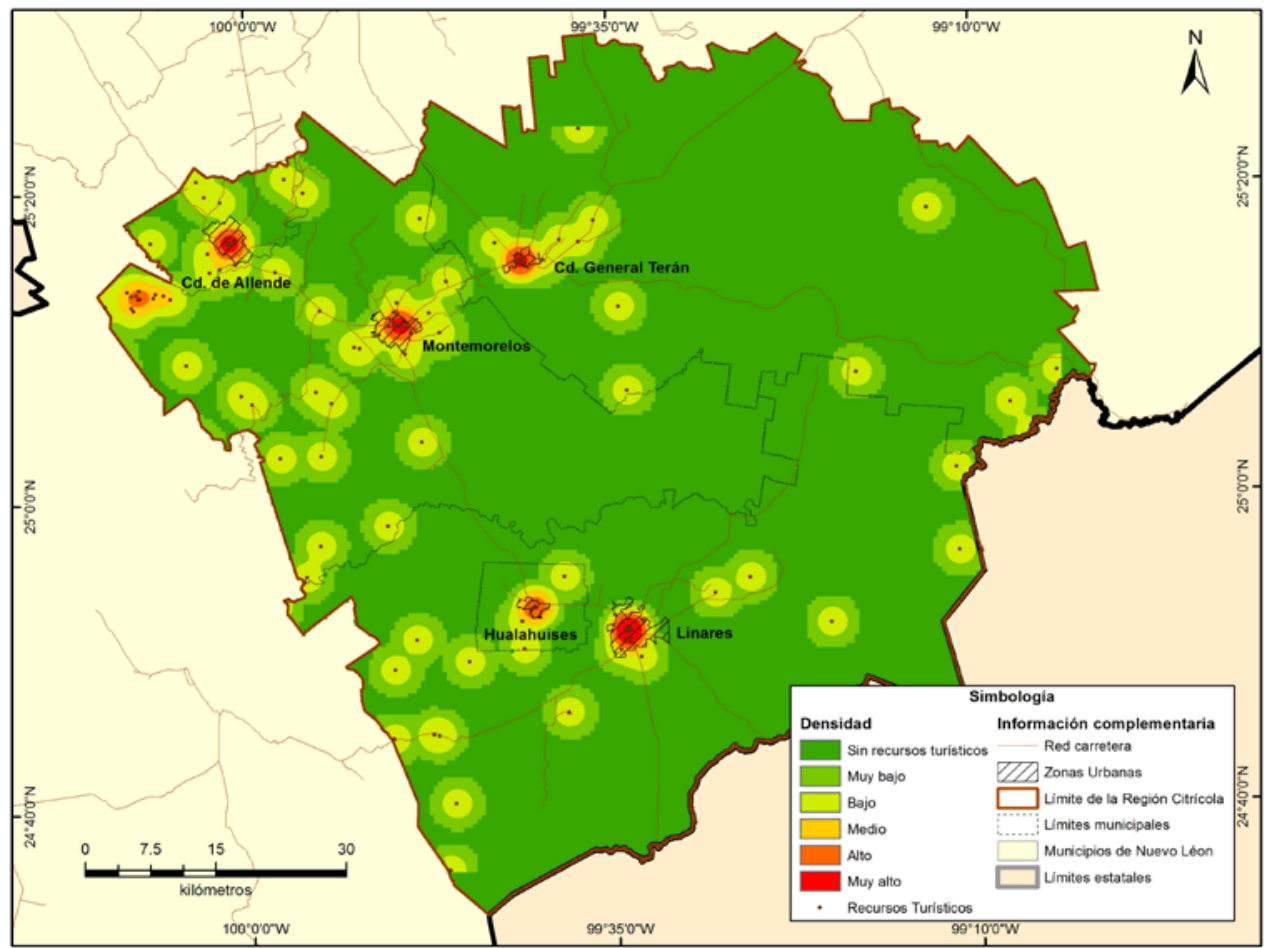

Fuente: elaboración propia.

9 Deporte extremo que requiere de habilidad física. La finalidad es derrotar al mayor número de oponentes utilizando una marcadora que a base de aire dispara cápsulas de pintura. La marca significa derrota. La práctica de este deporte se hace en espacios amplios y naturales, como bosques, campos y montañas. 


\subsection{Infraestructura de apoyo para el turismo}

La implementación de una actividad turística requiere de infraestructura básica para el establecimiento de un producto turístico capaz de satisfacer las necesidades de los visitantes (Jafari, op . cit.; Sectur, s.a.-b; Vera, López, et al., 2013). Entre los elementos identificados están las localidades que cuentan con servicios básicos (agua potable, alcantarillado, electricidad, teléfono o Internet ${ }^{10}$ ); es decir, aquellos núcleos de población que podrían desarrollar una planta turística de alojamiento, alimentación y otros servicios para los visitantes.

En la Región Citrícola se encuentran 141,611 viviendas, distribuidas de la siguiente manera: 37 por ciento en Linares, 33 por ciento en Montemorelos, 17 por ciento en Allende, ocho por ciento en General Terán y cuatro por ciento en Hualahuises. El municipio con mayor proporción de viviendas con agua potable, energía eléctrica y drenaje es Allende (69 por ciento), seguido de Linares (65 por ciento), Montemorelos y Hualahuises ( 58 por ciento en ambos casos) y General Terán (52 por ciento). En cuanto a la telefonía, 33 por ciento de las viviendas de Allende cuentan con ese servicio; le siguen Hualahuises, con 29 por ciento, Linares, con 28 por ciento, Montemorelos, con 25 por ciento, y General Terán, con 22 por ciento. Finalmente, Allende presenta la proporción más alta de viviendas con conexión a Internet (18 por ciento), seguido de Montemorelos y Linares (15 por ciento en ambos casos), Hualahuises (12 por ciento) y General Terán (siete por ciento) (INEGI, 2012a).

En lo que respecta a las localidades, de las 1,250 que integran la Región Citrícola sólo 371 (30 por ciento) cuentan con alguno de los cinco servicios básicos considerados. En Montemorelos se concentra 39 por ciento de estas localidades, en Linares 29 por ciento, en General Terán 16 por ciento, en Allende 11 por ciento, y en Hualahuises cuatro por ciento. Los municipios más grandes concentran la mayoría de las localidades, lo que contrasta con la gran dispersión de los asentamientos rurales. En cada municipio, las zonas urbanas y las carreteras (la nacional y la que va de Montemorelos a Reynosa) actúan como polos y ejes de concentración. El mayor número de localidades dotadas de servicios se da hacia el noroeste de la región, cerca de la Zona Metropolitana de Monterrey y, en segundo lugar, hacia el sur, en torno a las ciudades de Linares y Hualahuises. En cuanto a la densidad en términos de infraestructura, 42 por ciento de las localidades presenta baja densidad, 23 por ciento densidad muy baja, 21 por ciento densidad media, 12 por ciento alta densidad, y dos por ciento muy alta densidad (Figura 3).

10 Los servicios de teléfono e Internet se han vuelto parte esencial de la vida cotidiana, como medios de comunicación y como canales para compartir experiencias de manera inmediata. 


\section{Figura 3 \\ CARACTERÍSTICAS Y DENSIDAD DE INFRAESTRUCTURA POR LOCALIDAD (2010)}

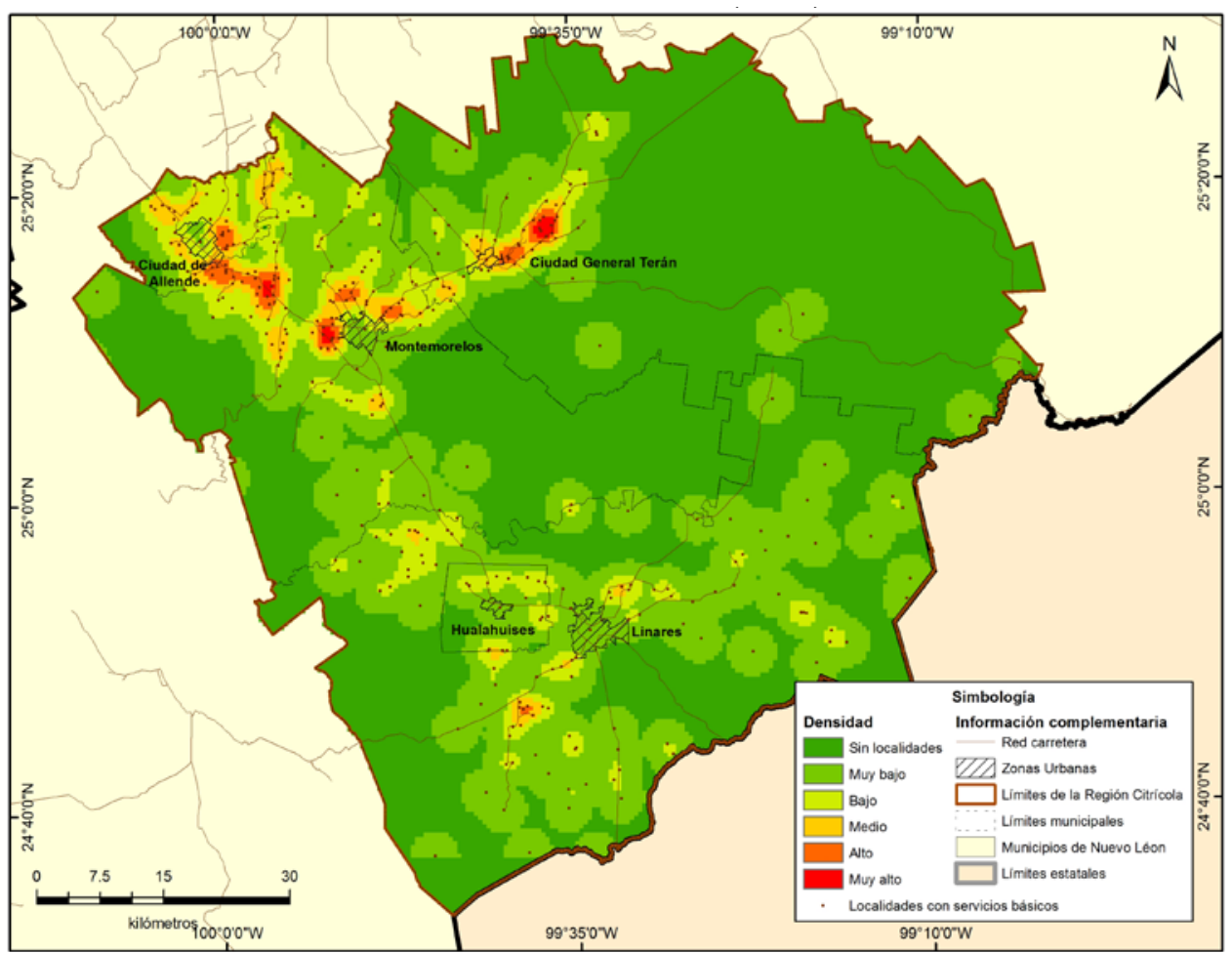

Fuente: elaboración propia.

\subsection{Servicios de vínculo turístico}

La Región Citrícola cuenta con 12 hoteles, cinco de ellos en Linares, otros cinco en Montemorelos y dos en Allende. La mayoría se clasifica como de cuatro estrellas y hay un "hotel boutique". Más de la mitad de los hoteles cuenta con entre 10 y 20 habitaciones, y el total de habitaciones en la región es de 311. Otro componente turístico importante es el de los restaurantes, que en muchos casos difunden la cultura culinaria de la región o del país. En la Región Citrícola existen 16 restaurantes concentrados, al igual que los hoteles, en las ciudades: Linares cuenta con seis, Montemorelos con cinco, y Allende con tres.

En lo que respecta al transporte de pasajeros, el turismo de la región depende enteramente de las carreteras, ya que el uso de las aeropistas y la vía ferroviaria se destina al transporte de productos comerciales. Las principales carreteras son la Nacional y la que va de Montemorelos a Reynosa; la primera une a Monterrey con Ciudad Victoria, y la segunda es una conexión internacional. Los municipios que cuentan con terminal de auto- 
buses son Allende (principal conector regional), Hualahuises, Linares y Montemorelos, las empresas transportistas que operan son Grupo SENDA y Autobuses del Norte, ambas conectan a las localidades de la región con otras ciudades del país y de Estados Unidos ${ }^{11}$ (Figura 4).

\section{Figura 4}

\section{DENSIDAD DE LOS SERVICIOS TURÍSTICOS, 2012}

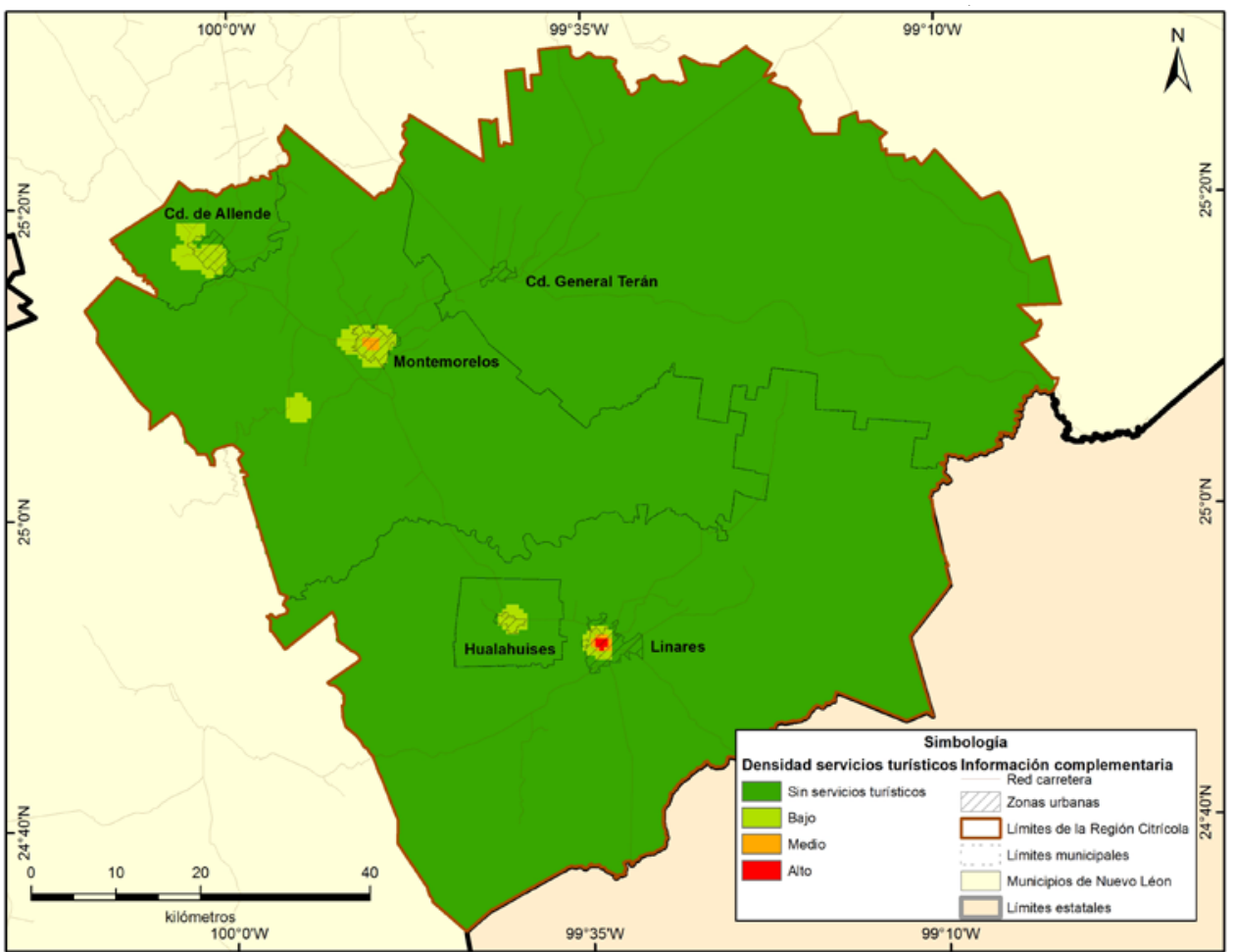

Fuente: Elaboración propia.

\subsection{Accesibilidad regional}

La accesibilidad desde distintas localizaciones geográficas es un factor clave para el desarrollo turístico e implica conexiones nodales rápidas entre los sitios de procedencia de los turistas, los servicios y los recursos de interés turístico. En la Región Citrícola se identificaron dos núcleos principales con un tiempo de recorrido promedio de 20 minutos:

11 Principales destinos nacionales: Piedras Negras, Ciudad Acuña, Monclova, Sabinas, Reynosa, San Luis Potosí, Tampico, Ciudad Valles, Ciudad Victoria y Laredo. Principales destinos a Estados Unidos: San Antonio, Houston, Dallas, Garland, Atlanta, Mobile, Montgomery, Raleigh, Chicago, Arkansas, San Diego, Charlotte, Greenville, Dallas, Durham. 
el primero es el eje Montemorelos que comunica con Ciudad Allende y General Terán, y el segundo es la carretera entre las localidades de Linares y Hualahuises. El tiempo de recorrido promedio entre las ciudades de Allende y Linares es de 80 minutos. Del norte de la región al extremo sur de la Zona Metropolitana de Monterrey (Santiago) median aproximadamente 20 minutos, y de ahí al centro de la ciudad son otros 20 a 40 minutos. La zona menos accesible es la Sierra Madre Oriental, con un tiempo de traslado que va de 60 a 140 minutos (Figura 5).

\section{Figura 5 \\ ACCESIBILIDAD EN LA REGIÓN CITRÍCOLA}

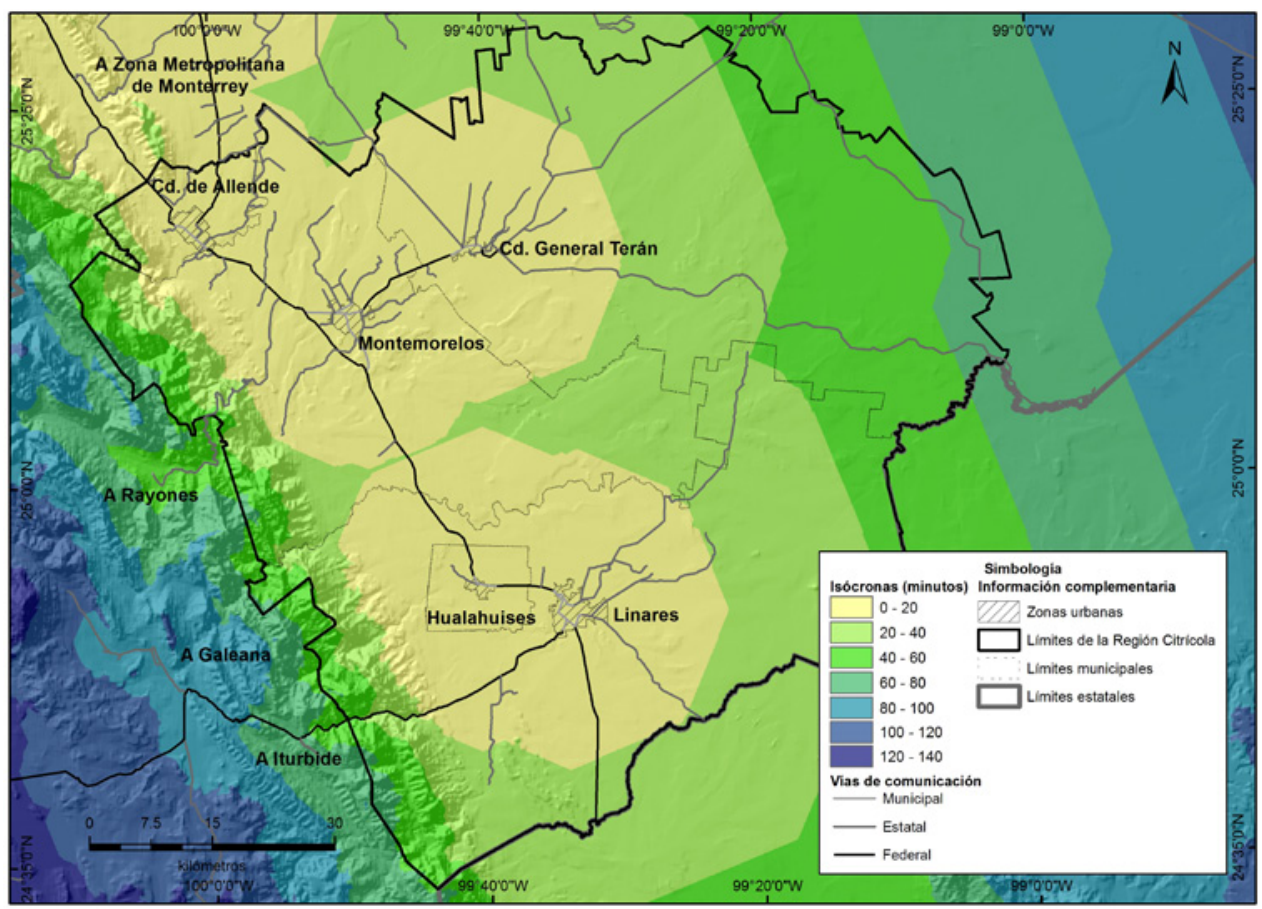

Fuente: elaboración propia.

\subsection{Espacios potenciales para el fomento del agroturismo}

En la Región Citrícola se distinguen dos áreas con potencial agroturístico: 1) un corredor en forma de arco que tiene sus nodos en las ciudades de Allende, Montemorelos y General Terán con sus áreas de influencia directa, con valores alto y muy alto, y 2) un arco que no logra constituir un corredor, que va de las localidades de El Cangrejo y La Cruz (al sur de Hualahuises) hasta La Florida y Vista Hermosa (al suroeste de ciudad Linares), cuyas áreas nodales son las cabeceras municipales de Hualahuises y Linares, con valores muy alto y alto. 
Las zonas con las densidades más altas son las cabeceras municipales, que concentran la industria citrícola, los recursos de interés turístico, las localidades con servicios básicos, la infraestructura turística y la accesibilidad, y se encuentran cercanas a los sitios de cultivos de cítricos. Las áreas con potencial muy alto y alto se ubican sobre la planicie de la Región Citrícola, por lo general próximas a cuerpos de agua (ríos, presas y lagos). Aquellas con nivel muy bajo y bajo son principalmente las de la Sierra Madre Oriental y la porción regional al oriente de General Terán, Montemorelos y Linares, caracterizadas por la falta de infraestructura vial entre las ciudades y los recursos de interés, así como la ausencia de hoteles y restaurantes (Figura 6).

\section{Figura 6 \\ ZONAS CON POTENCIAL PARA EL FOMENTO DEL TURISMO REGIONAL}

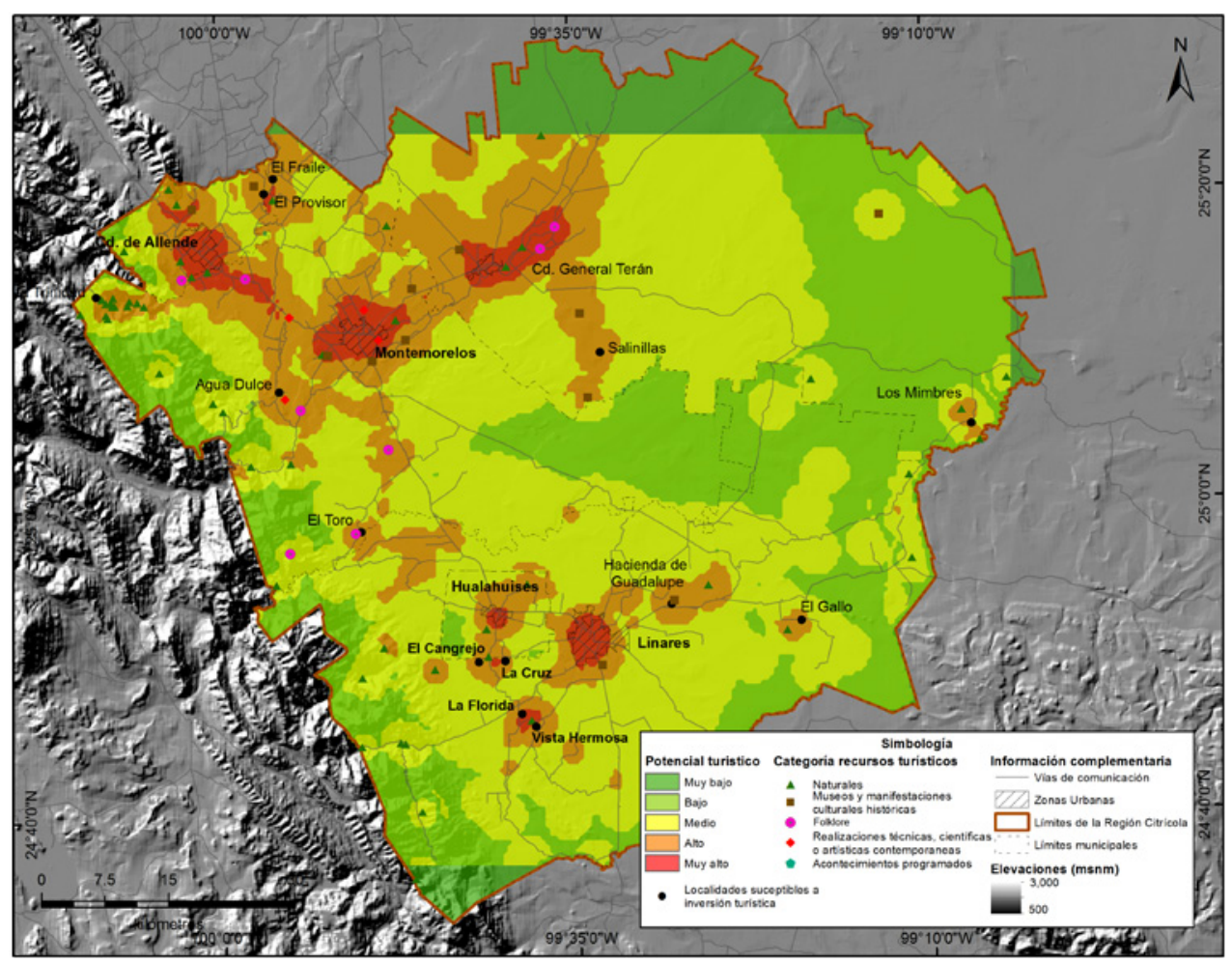

Fuente: elaboración propia.

\section{DISCUSIÓN}

En la última década del siglo XX e inicios del XXI, comenzó en México la diversificación de los productos turísticos sobre la base de la sustentabilidad, lo cual supuso la creación de nuevos proyectos de turismo alternativo. Sin embargo, los programas 
turísticos y las inversiones siguieron dirigiéndose a los destinos de playa, enfocándose al mejoramiento o creación de nuevos atractivos en los centros ya existentes y en la construcción de nuevos complejos sobre el litoral, y relegando a un segundo plano el desarrollo e inversión en proyectos alternativos (Poder Ejecutivo Federal, 2007; Sectur, 2006 y 2007b). No obstante, es evidente el aprovechamiento de las zonas rurales y naturales con fines turísticos, a las cuales se les han asignado funciones de esparcimiento, recreación, educación y cultura. Esto se evidencia en el Directorio de prestadores de servicios de turismo de naturaleza, compilado por la Secretaría de Turismo, en el que figuran 576 empresas que ofrecen 427 actividades ecoturísticas, 389 de aventura y 104 de turismo rural (Sectur, 2012). La proliferación del turismo alternativo ha procedido desde lo local, es decir, son los gobiernos locales y la población los que han planeado, adaptado e implementado, actividades turísticas relacionadas con la naturaleza y la cultura en los espacios que habitan. En el caso concreto del agroturismo, se trata de propuestas de la iniciativa privada, pues son los agricultores quienes han abierto la posibilidad de visitar y conocer los procesos de producción de sus áreas de cultivo, y en algunos casos los procesos de transformación de la agroindustria. Desafortunadamente, la ausencia de normatividad en este tipo de turismo ha conducido a la creación de proyectos fallidos o poco exitosos. En algunos casos, esto se debe a la falta de alguno de los elementos del sistema turístico o de integración de éstos en un mismo espacio. Así pues, el primer paso en la planificación turística debe ser la ubicaión de los elementos del sistema turístico.

La elaboración del presente estudio requirió la revisión de diversas propuestas relacionadas con la medición del potencial turístico, como las de Andrade y Mendoza, 2015; Bringas, 2010; Enríquez et al., 2010; Manzato y Rejowski; 2007; Mikery y Pérez, 2014; Milla, Mazariegos, Martínez y Arévalo, 2014; Sectur, s/f-a; Sosa y Salido, 2013. Estas propuestas se distinguen por identificar y describir los recursos de interés turístico, las actividades recreativas de acuerdo con el tipo de recurso, la infraestructura y el equipamiento disponible. La mayor parte de ellas determina el potencial turístico mediante la ponderación de las características de cada uno de los elementos. Para esta investigación se tomaron en cuenta los elementos turísticos considerados en dichos estudios, adaptando las variables pertinentes al turismo rural con actividades agropecuarias. La metodología no obstante se diferencia en el lugar primordial que otorga a la distribución y la relación espacial. Cada elemento se ubica en un mapa para señalar los lugares en que coincide con otros, y la valoración de las zonas con potencial turístico depende de la concentración o dispersión (densidad) de las variables deseadas. Para que la planeación turística sea viable y tenga éxito, es necesario considerar al conjunto de elementos del sistema turístico.

Los resultados de la investigación permitieron definir tres tipos de zonas: 1) zonas de potencial alto y muy alto, en las que la implementación de una actividad turística puede realizarse a corto plazo, 2) zonas de potencial medio que requieren de fuertes inversiones para el desarrollo de un producto agroturístico, y 3) zonas de potencial bajo y muy bajo, en las que el turismo no es viable. Las primeras se ubican en las cabeceras municipales y sitios aledaños, por lo que podría considerárseles de turismo urbano y cultural inmerso en zonas rurales. Si bien en estas áreas se concentran todos los elementos deseables, es 
necesario realizar una evaluación a profundidad para determinar la calidad de los recursos y la infraestructura de acogida para los visitantes. En las zonas de potencial medio, la ausencia de alguno de los factores seleccionados dificulta la planeación turística. Estas zonas se ubican por lo general en áreas de cultivo de cítricos, y aunque en algunas localidades es posible desarrollar una infraestructura para atención al turista, carecen de servicios turísticos, o la accesibilidad es limitada y los recursos turísticos se encuentran alejados unos de otros. Estos espacios se localizan en áreas rurales y en la Sierra Madre Oriental, donde el turismo podría dirigirse principalmente al ecoturismo y turismo de aventura, y su planificación debe proyectarse a mediano plazo. Finalmente, en las zonas con potencial bajo y muy bajo es necesario definir una nueva estrategia económica adecuada a las características del territorio.

Por las características del cultivo la Región Citrícola de Nuevo León tiene la posibilidad de desarrollar una "ruta de los cítricos" sustentada en las características físicas y sociales del territorio, en el que la citricultura funja como complemento de los atractivos culturales y naturales. Su propósito debe ser vincular las zonas con potencial muy alto y alto con las de potencial medio y bajo, a fin de propiciar el desarrollo local de toda la región. Resulta por ello necesario realizar una inversión para mejorar la infraestructura, la accesibilidad y adaptar las viviendas para el alojamiento de los visitantes en sitios cercanos a los recursos turísticos. Tal es el caso de localidades como La Trinidad, Agua Dulce, El Fraile, El Provisor y El Toro, en Montemorelos; la Hacienda de Guadalupe y El Gallo, en Linares, Salinillas y Los Mimbres, en General Terán (Figura 6). Actualmente, la región podría distinguirse como una "unidad turística" (Cárdenas, 2006: 25-31), ya que el equipamiento turístico se encuentra poco desarrollado y los recursos turísticos se aglomeran en un puñado de sitios frecuentados por visitantes de la Zona Metropolitana de Monterrey (uno de los nodos emisores de turistas más importantes del país) y de Estados Unidos.

La implementación del agroturismo en la Región Citrícola puede traer consigo grandes beneficios para la población y la economía local, como son: frenar el cambio de uso de suelo y alentar la continuidad de la actividad agrícola; fomentar la valoración de las costumbres y la cultura local; constituirse en una fuente de ingreso no agrícola para la población; contribuir a la conservación de los paisajes naturales y culturales; promover el mejoramiento de la infraestructura básica, y generar un desarrollo local equitativo. Es necesario que el turismo sea planeado de manera integral para que sea capaz de retener por más de un día a los visitantes, pues de no ser así se corre el riesgo de que la región se convierta en un espacio de recepción de excursionistas, y con ello se nulifiquen los beneficios a la población local. Otro aspecto importante es que sea una actividad incluyente que tome en cuenta a todos los estratos de la población, es decir, que se le pueda asignar diferentes roles a los habitantes para que a partir de distintas labores puedan ser incluidos en el turismo y no saquen provecho únicamente los grandes empresarios. Por último, es necesario remarcar que el turismo no es la solución a los problemas económicos, sociales y ambientales; por el contrario, si éste no es bien planeado puede acentuarlos o incluso generar otros. 


\section{CONCLUSIONES}

El aprovechamiento de espacios agropecuarios con fines turísticos es una alternativa viable para el desarrollo de algunas regiones de México, y la identificación de los sitios que reúnen las características necesarias para la implementación de una actividad turística es una tarea de primer orden en la planeación territorial. La citricultura en Nuevo León ha influido en la configuración territorial, la cultura y la economía del estado, conformando un paisaje atractivo para el desarrollo de una actividad agroturística complementada por recursos naturales (la Sierra Madre Oriental, los ríos de las planicies) y sociales (arquitectura, gastronomía, fiestas patronales, etcétera).

La aplicación de un análisis de álgebra de mapas permitió identificar las áreas con potencial turístico en la Región Citrícola. El análisis mostró que son las zonas urbanas las que tienen la posibilidad de desarrollar el turismo a corto plazo, debido a que cuentan con los elementos necesarios para sostener una actividad turística. Adicionalmente se identificaron zonas con recursos de interés turístico natural que pueden representar un atractivo para los turistas; si bien para ello es necesario invertir en una infraestructura que permita a la población local aprovechar económicamente esos espacios. La región cuenta con establecimientos de alojamiento y alimentación que hacen posible recibir y atender a los turistas, además de una carretera que conecta las cabeceras municipales con ciudades importantes como Monterrey, Ciudad Victoria y otras en Estados Unidos, lo cual asegura la afluencia de visitantes a la región.

Más allá de las zonas urbanas que han sido reconocidas como las de mayor potencial turístico en función de la metodología que se ha aplicado a la Región Citrícola, los autores de este trabajo reconocen que en la región existen muchos otros sitios con atractivo de interés turístico que hoy en día son demandados en el turismo cultural, de aventura, científico, etcétera; sin embargo, estos espacios no pueden ser reconocidos con un elevado potencial turístico a pesar de su singular belleza o de estar plagados de riqueza cultural pues, en el inmediato y mediano plazos, estos lugares no podrán ser accesibles a los turistas promedio que demandan de servicios estandarizados en transporte, hospedaje y alimentos. Esta situación se agrava por el momento, pues el aventurarse a sitios inaccesibles en el noreste de México supone un riesgo significativo en términos de la seguridad.

\section{BIBLIOGRAFÍA}

ALONSO, J. (2002): Geografía turística: general y de España. Madrid, Centro de Estudios Ramón Areces, S.A.

ANDRADE, L.; MENDOZA, H. (2015): «Paisaje natural y cultural del cacao fino de aroma como oferta agroturística en Manabí», Espamciencia, nº 6, pp. 17-24.

ANDREI, J.; DARVASI, D. (2012): «Perspective and Challenges in Financing the New Common Agricultural Policy, A New Paradigm», Journal of Food, Agriculture \& Enviroment, vol. 10, $\mathrm{n}^{\mathrm{o}}$ 1, pp. 904-907.

ANTÓN, S. et al. (2005): Planificación territorial del turismo. Barcelona, Editorial UOC. BARBINI, B. (2003): «Viabilidad del turismo productivo agropecuario en el interior Bonaerense», Aportes y transferencia, año 7, vol. I, pp. 97-108. 
BARRERA, E. (2013): «Las condiciones de éxito en la construcción de las rutas alimentarias», Redmarka: revista académica de marketing aplicado, año VI, vol. I, nº 6, pp. 21-49.

BARRERA, E. (2006): Rutas alimentarias, una estrategia cultural para el desarrollo rural mexicano. México, CONACULTA.

BARRERA, E.; BRINGAS, O. (2008): «Las rutas alimentarias: una arquitectura turística basada en la identidad de los alimentos», Gastronomic Sciences, no 8, pp. 1-11.

BLANCO, M. (2008): Guía para la elaboración del plan de desarrollo turístico de un territorio. San José, Instituto Interamericano de Cooperación para la Agricultura.

BLANCO, M.; RIVEROS, H. (2010): «La multifuncionalidad de la agricultura: implicaciones para el análisis de los sistemas agrarios», en Multifuncionalidad agraria. Desarrollo rural y políticas públicas: Nuevos desafíos para la agricultura. Junta de Andalucía, pp. 117-126.

BOUlLón, R.; BOULLÓN, D. (2008): Turismo rural. Un enfoque global. México, Trillas.

BRINGAS, O. (2010): Rutas alimentarias. Identificación de elementos básicos para su creación en la sierra alta de Sonora. Hermosillo. Universidad Autónoma de Coahuila.

CALATRAVA, J. (2009): «Oferta y demanda social por la multifuncionalidad agraria en el diseño de políticas públicas: Estado de la cuestión», en Desarrollo de los agronegocios y la agroindustria rural en América Latina y el Caribe. Instituto Interamericano de Cooperación para la Agricultura, pp. 45-58.

CÁRDENAS, F. (2006): Proyectos turísticos, localización e inversión. México, Trillas.

CONARTE NUEVO LEÓN (2005): Compilación de Leyendas: Región Citrícola de Nuevo León. Monterrey, Consejo para la Cultura y las Artes de Nuevo León.

CONARTE NUEVO LEÓN (2006): Crónicas municipales del estado de Nuevo León. Monterrey, Consejo para la Cultura y las Artes de Nuevo León.

CONSTABEL, S. et al. (2007): Agroturismo en Chile. Caracterización y perspectivas. Santiago, Gobierno de Chile y Universidad Austral de Chile.

CORONADO, S.; QUINTANILLA, M. (2008): General Terán y su gente. Tierra con olor a azahar. Monterrey, Editorial Montemorelos.

ENRÍQUEZ, M. et al. (2010): «Evaluación multicriterio de los recursos turísticos del parque estatal Sierra de Nanchitla, estado de México», El Periplo Sustentable, $\mathrm{n}^{\circ} 18$, pp. 7-35.

ESCUDERO, G. (2003): «Agroturismo. El negocio del siglo XXI», Boletín mensual del Instituto Interamericano de Cooperación para la Agricultura IICA, n ${ }^{\circ}$, pp. 1-3.

ESRI (2013): «Densidad de Kernel (Spatial Analysis)» en ArcGIS Resource Center, 9 de junio de 2013. ESRI Press. Disponible en http://www.rlc.fao.org/es/desarrollo/fao-bid/ des/pdf/leon.pdf

ESRI. (2006): A to Z SIG. Nueva York, ESRI Press.

FERNÁNDEZ, A. (2004): «Turismo y ordenación del territorio», Quaderns de Política Económica, vol. 7, pp. 35-47.

GARCÍA, R. (2011): «Turismo y desarrollo rural en la comarca del Noreste de la región de Murcia: loas programas europeos Leader», Cuadernos de Turismo, nº 27, pp. 419-435. 
GOBIERNO DEL ESTADO DE NUEVO LEÓN (2013): «Conoce Nuevo León, hoteles, cabañas y restaurantes en la Región Citrícola», Secretaría de Turismo de Nuevo León, 12 de Marzo de 2013. Disponible en http://www.nl.gob.mx/?P=turismo.

GÓMEZ, M.; BARREDO, J. (2006): Sistemas de Información Geográfica y evaluación multicriterio en la ordenación territorial. México, Alfaomega.

GONZÁLEZ, M. (2011): «Una propuesta para desarrollar turismo rural en los municipios de Zacatecas, México: las rutas agro-culturales», Pasos. Revista de turismo y patrimonio cultural, vol. 9, $\mathrm{n}^{\circ} 1$, pp. 129-145.

GONZÁLEZ, M. (2009): «Las rutas agro-alimentarias y culturales, una opción de turismo rural para los municipios de Zacatecas, México», Topofilia. Revista de Arquitectura, urbanismo y ciencias sociales, vol. I, $\mathrm{n}^{\circ} 3$, pp. 1-14.

HORTELANO, L. (2015): «El patrimonio territorial como activo turístico en la "raya" de Castilla y León con Portugal», Cuadernos de Turismo, n 36, pp. 247-268.

IICA (2008): La contribución del IICA al desarrollo de la agricultura y las comunidades rurales de las Américas. Buenos Aires, Instituto Interamericano de Cooperación para la Agricultura.

INAFED (2013): «Estado de Nuevo León», en Enciclopedia de los municipios y delegaciones de México, 23 de Enero de 2013. Instituto Nacional para el Federalismo y el Desarrollo Municipal. Disponible en http://www.e-local.gob.mx/wb2/ELOCAL/ EMM_nuevoleon.

INEGI (2013): «Sistema para la consulta del Anuario Estadístico de Nuevo León, 2012», en Anuarios Estadísticos, 29 de Enero de 2013. Instituto Nacional de Estadística y Geografía. Disponible en: http://www.inegi.org.mx/est/contenidos/espanol/sistemas/ aee12/estatal/nl/default.htm.

INEGI (2012a): Principales resultados por localidad (ITER), 2010. México, Instituto Nacional de Estadística y Geografía.

INEGI (2012b): Sistema Estatal y Municipal de Base de Datos. México, Instituto Nacional de Estadística y Geografía.

JAFARI, J. (2000): Enciclopedia del turismo. Madrid, Editorial Síntesis.

JIMÉNEZ, V. (2010): Nuevo León, Guía práctica para descubrir los encantos del estado. Delicioso viaje por sus recetas de cocina más tradicionales. México, Océano.

KASPAREK, M. (2009): El agroturismo y la variedad agropecuaria. Eschborn, Deutsche Gesellschaft für Technische Zusammenarbeit (GTZ).

KING, J. (2009): Plan de desarrollo urbano para la Región Cítrica del Estado de Nuevo León. Monterrey, Gobierno del Estado de Nuevo León.

KING, J. (2006): Plan estratégico para el desarrollo sostenible de la Zona Citrícola del Estado de Nuevo León. Monterrey, Gobierno del Estado de Nuevo León, Fideicomiso para el Desarrollo de la Zona Citrícola de Nuevo León, Consejo Nacional Ciencia y Tecnología y Fondos Mixtos.

LEDESMA, F. (2014): La multifuncionalidad del medio rural en España: experiencia de desarrollo territorial rural en Andalucía. México, Procuraduría Agraria y Secretaría de Desarrollo Agrario, Territorial y Urbano.

LIZAMA, F. (2013): «Plan de acción turística de la ruta del cacao al chocolate», Revista iberoamericana para la investigación y el desarrollo educativo, nº 11 pp. 1-20. 
LOBO, R.; et al. (1999): «Agritourism Benefits Agriculture in San Diego County», California Agriculture, vol. 53, $\mathrm{n}^{\circ}$ 6, pp. 20-24.

LOMINÉ, L.; EDMUNDS, J. (2007): Key Concepts in tourism. Nueva York, Palgrave Macmillan.

LOPEZ, E. y TRIBAK, A. (2013): «Establecimiento de la ruta turística «Taza-Bouiblane» como instrumento para la promoción del turismo rural y ecológico en el medio Atlas Nororiental (Marruecos)», Cuadernos de Turismo, n 31, pp. 175-198.

LÓPEZ, A.; CUKIER, J.; SÁNCHEZ, A. (2006): «Segregation of Tourist Space in Los Cabos, Mexico», Tourism Geographies: An International Journal of Tourism Space, Place and Environment, vol. 8, $\mathrm{n}^{\circ} 4$, pp. 359-379.

LÓPEZ, A. et al. (2014): «Delimitación territorial», en Región Citrícola de Nuevo León. Su complejidad territorial en el marco global. México, Instituto de Geografía, UNAM/ Facultad de Ciencias Forestales, pp. 17-27.

LÓPEZ, T.; BARRENA, R. (2013): «Preferencias del visitante de establecimientos del turismo rural. Estudio en Navarra», Cuaderno de Turismo, n 32, pp. 141-153.

MANZATO, F.; REJOWSKI, M. (2007): «Turismo cultural. Evaluación del potencial turístico de sitios arqueológicos», Estudios y Perspectivas en Turismo, vol. 16, pp. 72-95.

MELÉNDEZ, A. (2009): «Agroturismo en Chile. Caracterización y perspectivas», Estudios y Perspectivas en Turismo, vol. 18, $\mathrm{n}^{\circ} 3$, pp. 357-361.

MIKERY, M. PÉREZ, A. (2014): «Métodos para el análisis del potencial turístico del territorio rural», Revista Mexicana de Ciencias Agrícolas, n 9, pp. 1729-1740.

MILLA, A.; MAZARIEGOS, A.; MARTÍNEZ, J.; ARÉVALO, O. (2014): «Factibilidad de un desarrollo agroturístico en la comunidad Agua Caliente, del municipio de Cacahoatán, Chiapas», Sexta Época, año XVIII, vol. 34, pp. 740-748.

MINECITUR (2006): Manual para la formulación del inventario de recursos turísticos a nivel nacional (Fase I - Categorización). Lima, Dirección Nacional de Desarrollo Turístico.

MORENO, A. (2008): Sistemas y análisis de la información geográfica. Manual de autoaprendizaje con ArcGIS. México, Alfaomega.

NIEVA, A. (2004): Turismo alternativo. Una nueva forma de hacer turismo. México, Secretaría de Turismo.

ORDÓÑEZ, J. (2007): Región Citrícola de Nuevo León. Monterrey, Fondo Editorial de Nuevo León/ Fidecitrus.

ORTIZ, T. (2009): Bordando paradigmas para el desarrollo. Metodología para abordar el turismo rural desde el sujeto social. México, UAM Xochimilco/Universidad Latina.

PAÜL, V.; ARAÚJO, N. (2012): «Agroturismo en entornos periurbanos: enseñanza de la iniciativa holeriturismo en el Parc Agrari del Baix Lloregat (Cataluña)», Cuadernos de Turismo, $\mathrm{n}^{\mathrm{O}} 29$, pp. 183-208.

PODER EJECUTIVO FEDERAL (2007): Plan Nacional de Desarrollo 2007-2012. México, Presidencia de la República.

POLOVITZ, N. (2001): «Agritourism: Motivations Behind Farm/Ranch Business Diversification», Journal of Travel Research, vol. 40, $\mathrm{n}^{\circ}$ 1, pp. 19-26. 
PONCE, M. (2009): «Agroturismo y desarrollo rural en destinos turísticos del interior. El caso de Finca Hacienda Los Granadicos en Moratalla (Murcia)», Cuadernos de Turismo, $\mathrm{n}^{\mathrm{o}} 24$, pp. 193-206.

PULIDO, J.; CÁRDENAS, P. (2011): «El turismo rural en España. Orientaciones estratégicas para una tipología aún en desarrollo», Boletín de la Asociación de Geógrafos Españoles, $\mathrm{n}^{\circ}$ 56, pp. 155-176.

RIVAS, F. (2002): Agroturismo, una alternativa para el desarrollo económico de la zona rural, en Fomento al ecoturismo como herramienta de desarrollo económico. Chalatenango, Asamblea Legislativa.

RIVEROS, H.; BLANCO, M. (2003): El agroturismo, una alternativa para revalorizar la agroindustria rural como mecanismo de desarrollo local. Lima, IICA, PRODAR.

ROCHA-PEÑA, M. (2009): «Los cítricos en el estado de Nuevo León», en El cultivo de los cítricos en el estado de Nuevo León. México, Instituto Nacional de Investigaciones Forestales, Agrícolas y Pecuarias, pp. 19-26.

SAGARPA (2012): «Servicio de Información Agroalimentaria y Pesquera», en Sistema de información, 20 de Noviembre 2013. Secretaría de Agricultura, Ganadería, Desarrollo Rural, Pesca y Alimentación. Disponible en http://www.siapp.gob.mx/.

SÁNCHEZ, S.; ALCUDIA, P.; BEJARANO, J. (2005): «Turismo sostenible y desarrollo local rural: apuntes metodológicos», en Turismo sostenible: Un enfoque multidisciplinar e internacional. México, Universidad de Córdoba, pp. 453-467.

SÁNCHEZ, V. (1990): «Evolución económica de la Región Citrícola», en La Región Citrícola de Nuevo León: Actores, condiciones y perspectivas. Monterrey, Facultad de Filosofía y Letras UANL/El Colegio de la Frontera Norte, pp. 9-38.

SCT (2012): Atlas de la red carretera de México. México, Instituto Mexicano del Transporte.

SECTUR (2012): Directorio de prestadores de servicios de turismo de naturaleza en México. México, Secretaría de Turismo.

SECTUR (2007a): Elementos para evaluar el impacto económico, social y ambiental del turismo de naturaleza en México. México, Cestur/Universidad Autónoma Metropolitana.

SECTUR (2007b): Programa Sectorial de Turismo 2007-2012. México, Secretaria de Turismo.

SECTUR (2006): Comportamiento, avances y perspectivas del turismo en México. México, Secretaría de Turismo/Fondo de Cultura Económica.

SECTUR (s.a.-a): Identificación de potencialidades turísticas en regiones y municipios. México, Secretaría de Turismo.

SECTUR (s.a.-b): Integración de agrupamientos turísticos competitivos. Clúster turísticos. México, Secretaría de Turismo.

SOLSONA, J. (2014): «Análisis prospectivo del turismo rural: el caso de la Comunitat Valenciana», Cuadernos de Turismo, $\mathrm{n}^{\circ} 34$, pp. 313-334.

SOSA, M.; SALIDO, P. (2013): «La conformación de una ruta alimentaria como estrategia de desarrollo turístico local para el municipio de Ures, Sonora, México», Estudios Sociales, $\mathrm{n}^{\circ} 42$, pp. 153-174. 
SUCHET, A.; JORAND, D.; TUPPEN, J. (2011): «La diversificación de la oferta turística en las estaciones de media montaña: el caso de La Chapelle en los Alpes Franceses del norte», Cuadernos de Turismo, no 28 , pp. 215-226.

SUNYER, N. et al. (2005): «Técnicas e instrumentos para el análisis territorial», en Planificación territorial del turismo. Barcelona, UOC, pp. 61-74.

VALSECA, M. (2009): «Inventario de recursos turísticos», Revista Digital Innovación y Experiencias Educativas, ${ }^{\circ} 20$, pp. 1-9.

VERA, J. et al. (2013): Análisis territorial del turismo y planificación de destinos turísticos. Valencia, Tirant Humanidades.

VOGEL, M. et al. (2004): Turismo rural, modalidad agroturismo: una alternativa de desarrollo para la zona norte de la provincia de Neuquen. Buenos Aires, Facultad de Turismo/Universidad Nacional del Comahue.

WEBB, R. (2013): Conexión y despegue rural. Lima, Universidad de San Martín de Porres/Instituto del Perú.

WTO (2004): Rural Tourism in Europe: Experience, Development and Perspectives. Nueva York, World Tourism Organization.

ZAMORA, J. et al. (s.a.): «Diseño de un prototipo de servicio de agroturismo a través de la acción-investigación», Gestión Turística, $\mathrm{n}^{\circ}$ 2, pp. 7-39.

ZÁRATE, M.; RUBIO, M. (2005): Geografía humana. Sociedad, economía y territorio. Madrid, Editorial Universitaria Ramón Acebes. 